\title{
Extending the record of photosynthetic activity in the eastern United States into the presatellite period using surface diurnal temperature range
}

\author{
Céline Bonfils, ${ }_{1}^{1}$ Alon Angert, ${ }^{1}$ Cara C. Henning, ${ }^{1}$ Sébastien Biraud, ${ }^{1}$ Scott C. Doney, ${ }^{2}$ \\ and Inez Fung ${ }^{1}$
}

Received 30 January 2005; revised 7 March 2005; accepted 17 March 2005; published 26 April 2005.

[1] In this study, we demonstrate that mid-latitude surface measurements of diurnal temperature range (DTR) can be used to reconstruct decadal variability of regional-scale terrestrial photosynthetic activity 1) during and prior to the period with satellite retrievals of land greenness and 2) without the need for moisture data. While the two relative maxima present in the seasonal evolution of DTR can determine the beginning and the end of the growing season, the summertime average DTR can be used as a proxy of summertime terrestrial photosynthesis. In a case study in the eastern United States (1966-1997), the DTR reconstructions indicate significant natural decadal variability in photosynthetic activity, but no secular, long-term trend. The summertime photosynthesis was found to be controlled primarily by moisture availability. Also, contrary to existing model parameterizations, the timing of spring onset was found to depend on both temperature and moisture. Citation: Bonfils, C., A. Angert, C. C. Henning, S. Biraud, S. C. Doney, and I. Fung (2005), Extending the record of photosynthetic activity in the eastern United States into the presatellite period using surface diurnal temperature range, Geophys. Res. Lett., 32, L08405, doi:10.1029/ 2005GL022583.

\section{Introduction}

[2] Understanding the decadal response of the terrestrial biosphere to climate variability and climate change requires a time record of photosynthesis longer than provided by the satellite-derived Normalized Difference Vegetation Index (NDVI) (1982 to present). Diurnal temperature range (DTR) signatures can be utilized to hindcast the long evolution of photosynthetic activity [Bonfils et al., 2004] (hereinafter referred to as B04). Because carbon assimilation and transpiration are simultaneously regulated by stomatal conductance in $\mathrm{C}_{3}$ plants, anomalously high photosynthesis is accompanied by an increase in latent heat loss that 1) strongly reduces the summertime daily maximum temperature and thus the DTR and 2) produces discontinuities in the seasonal evolution of these two variables when leaves emerge (as seen in observations [Schwartz, 1996], land surface models [Collatz et al.,

\footnotetext{
${ }^{1}$ Berkeley Atmospheric Sciences Center, University of California, Berkeley, California, USA.

${ }^{2}$ Marine Chemistry and Geochemistry, Woods Hole Oceanographic Institution, Woods Hole, Massachusetts, USA.
}

Copyright 2005 by the American Geophysical Union. 0094-8276/05/2005GL022583\$05.00
2000], and global climate models with prognostic leaf area [Levis and Bonan, 2004]). In the eastern United States, DTR exhibits a winter minimum and a local summer minimum framed between two maxima [Leathers et al., 1998]. According to Durre and Wallace [2001] the two peaks correspond to spring initiation and autumn termination. In addition, B04 showed that the variations in the summer "dip" are related to the variability in summer terrestrial photosynthetic intensity, particularly in temperate regions and water-limited ecosystems.

[3] In this study, we employ daily DTR observations from 1966 to 1997 at different stations located in the eastern US in order to: (1) detect the beginning and the end of the growing season as well as the intensity of summertime photosynthetic activity; (2) validate the detection method by comparing three DTR-photosynthetic indices to NDVI (and net primary productivity derived from it) and Lilac bloom proxies for growing season onset; and (3) hindcast and interpret the long term evolution of vegetation growth and activity prior to satellite observations.

\section{Data and Methodology}

[4] We examine daily surface measurements of maximum and minimum temperatures from the First Order Summary of the Day for the available stations in the eastern US $(101 \mathrm{~W}-55 \mathrm{~W})$, the most documented region in this dataset (http://ingrid.ldgo.columbia.edu/SOURCES/.NOAA/ .NCDC/.DAILY/.FSOD/). We select only time series of DTR (computed as the difference between daily maximum and minimum temperatures) that are at least $99 \%$ complete (162 stations, Figure 1). Because the photosynthesis-DTR relationship is valid only for $\mathrm{C}_{3}$ plants when there is local water limitation (B04), we eliminate 12 stations that do not display, in climatology, the expected growing season DTR depression. Cloudiness, identified as the major cause of DTR interannual variability [Dai et al., 1997], can strongly mask the influence of vegetation on DTR and obfuscate the detection of the summer "dip" observed in the seasonal evolution of DTR. To obtain the best signature of vegetation activity without information on daily cloudiness over this period, we create a composite time series, for each station, by selecting the maximum DTR over every 5-day period, the typical weather cycle in the eastern US. The technique is very similar to the compositing procedure used to minimize cloud contamination from NDVI data sets. Next, the time series of the cloud screened DTR are smoothed by using two successive 6-point running averages and then used to calculate, for each year, the mean midsummer (JJA) DTR 


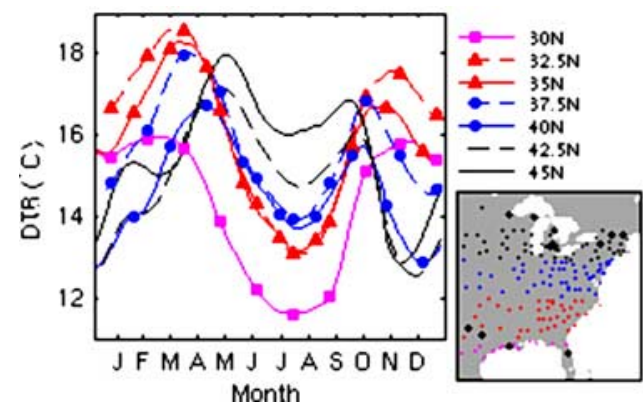

Figure 1. Climatological seasonal variation in the surface diurnal temperature range (DTR) in the eastern US averaged over the period 1966-1997 for all latitude bands; map of the stations kept (dots) and excluded $(+)$, color coded by latitude band.

and the day of year (DOY) of spring and autumn DTR maxima. Years with only one peak or indistinct peaks are excluded $(\sim 15 \%$ of the total years at each station, on average). Sensitivity experiments show that changing the number of days chosen for cloud screening, the number of points used for smoothing, or the way that the spring and autumn maxima are found lead to very similar results. We define three DTR indices: (1) Growing-season Onset DTR Index (GODI), the negative of the normalized anomaly in DOY of the spring DTR maximum; (2) Summer Photosynthesis DTR Index (SPDI), the negative of the normalized anomaly in JJA DTR; and (3) Growing-season Termination DTR Index (GTDI), the normalized anomaly in the fall DTR maximum DOY. The negative signs are included in definitions of GODI and SPDI so that positive index values reflect an earlier growing season or stronger photosynthetic activity, respectively. Each index is normalized, for each latitude band, by subtracting the seasonal mean and dividing by the seasonal standard deviation over the entire timerecord (1966-1997).

[5] To validate the summer and termination indices, we use monthly satellite-derived vegetation index (NDVI) and Net Primary Productivity (NPP) time-series from 1982 to 1997. NDVI fields in $1^{\circ}$ by $1^{\circ}$ spatial resolution are from GIMMS (the Global Inventory Modeling and Mapping Studies) version g [Tucker et al., 2005]. NPP time series are calculated with the CASA model [Randerson et al., 1996] using monthly interannual NDVI, temperature [Kalnay et al., 1996], and precipitation [Chen et al., 2002] data with climatological solar radiation fields [Bishop and Rossow, 1991]. For the validation of GODI, the bloom DsOY of Lilac (Syringa chinensis clone and Syringa vulgaris) [Schwartz and Caprio, 2003] are normalized for each station from $32 \mathrm{~N}$ to $40 \mathrm{~N}$ (map available at http:// www.ncdc.noaa.gov/paleo/phenology.html) and averaged together for each year from 1968 to 1981. These are the years during which the number of stations in this region exceeds 40 with a roughly uniform station coverage. Daily observations of DTR and Gross Primary Productivity (GPP) from Harvard Forest (Massachusetts, US) [Barford et al., 2001] are also examined.

[6] Finally, to interpret the DTR signals, we use temperature anomalies, calculated from the GISS dataset [Hansen et al., 1999], and soil-moisture variations, captured by the three month Standardized Precipitation Index (SPI3). SPI3 is the standardized sum of precipitation (from Chen et al. [2002]) over three months (starting two months before the month of interest).

\section{Results and Discussion}

\subsection{DTR Climatology}

[7] The seasonal changes in the climatological DTR are presented (similar to Durre and Wallace [2001]) by latitude bands centered at $30 \mathrm{~N}, 32.5 \mathrm{~N}, 35 \mathrm{~N}, 37.5 \mathrm{~N}, 40 \mathrm{~N}, 42.5 \mathrm{~N}$ and 45N (Figure 1). The latitude bands include 13, 16, 22, 17, 35, 36, and 11 stations respectively. Moving from the southern to the northern latitudes, the climatological seasonalities show that, as expected, the spring and the autumn peaks get closer together, reflecting a shorter plant growing season (the DOY of the peaks is highly correlated with latitude, $r=0.88,-0.85$ respectively). In summer, the DTR minimum value shows a general increasing trend with latitude, but with only a small trend between $32.5-40 \mathrm{~N}$; however, the CASA NPP does not show any latitudinal gradient for the region (not shown). B04 showed that the monotonic relationship between summer DTR and NPP varies with the land cover type, and the vegetation at $30 \mathrm{~N}$ (coastal stations), and $42.5 \mathrm{~N}$ to $45 \mathrm{~N}$ (stronger grassland influence) differs from that in $32.5 \mathrm{~N}$ to $40 \mathrm{~N}$ (largely deciduous forest), as shown in Figure 1. For this reason, we will focus only on $32.5 \mathrm{~N}$ to $40 \mathrm{~N}$ to ensure we are analyzing similar biomes.

\subsection{Validation of the DTR Indices}

[8] To validate the three DTR indices, we have averaged them from $32.5 \mathrm{~N}$ to $40 \mathrm{~N}$ and compared them to the mean NDVI, NPP, and Lilac bloom over the same region (Figure 2). SPDI is found to be correlated with the summer (JJA) NPP ( $\mathrm{r}=0.74, \mathrm{p}=0.001)$ and also somewhat correlated with summer NDVI $(\mathrm{r}=0.40)$. GODI is well correlated with the mean (inverse) Lilac bloom DOY ( $\mathrm{r}=$ $0.69, p=0.006)$. There is no appropriate proxy for fall termination. However, a later growing season termination is

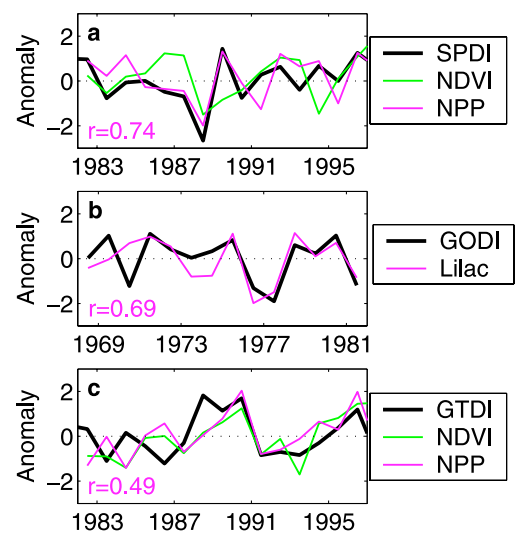

Figure 2. Comparison of the normalized anomalies in (a) SPDI with summer (JJA) satellite-derived vegetation index (NDVI) and CASA net primary production (NPP); (b) GODI with (inverse) Lilac Bloom DOY; (c) GTDI with fall (SON) NDVI and NPP. Correlation coefficients (r) are given for SPDI with summer NPP, GODI with Lilac bloom, and GTDI with fall NPP. 

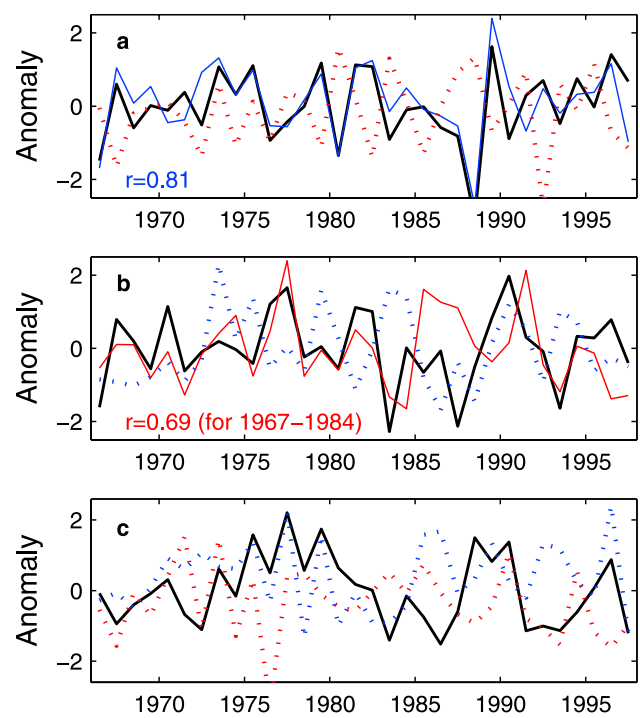

Figure 3. Comparison of the long-term variations in (a) SPDI, (b) GODI, and (c) GTDI (black) with the corresponding normalized anomalies in summer (JJA), spring (MAM) and fall (SON) temperature and precipitation expressed by SPI3 (red and blue, respectively). Most correlated climate time-series are indicated by a solid line, and correlation coefficient (r) is indicated.

expected to result in higher fall photosynthetic activity. Indeed, GTDI is correlated with the fall (SON) NPP $(r=$ $0.49, \mathrm{p}=0.06)$ and with fall NDVI $(\mathrm{r}=0.43)$.

[9] Another way to validate our DTR indices is to compare them with GPP (assumed to be linearly related to NPP) derived from flux tower measurements, and Harvard Forest is the only station that provides a long enough record for such analysis (1992-1999). B04 showed that the summertime DTR and GPP anomalies at this station are strongly correlated $(\mathrm{r}=0.85)$. Performing additional analyses of these daily time series of DTR and GPP, we find that the timing of the spring DTR peak (between May 10 and June 4$)$ is strongly correlated $(\mathrm{r}=0.9)$ with the beginning of the growing season (i.e., when the GPP slope is changing the most rapidly - i.e. the second derivative is maximized). The fall DTR peak (between Sept. 12 and Oct. 17) is slightly less, but still significantly, correlated $(r=0.7)$ with the end of the growing season.

[10] These two independent validations suggest the DTR indices are capturing the interannual variations in the NPP and growing season length well.

\subsection{Long-Term Photosynthetic Variability in the Eastern US}

[11] Using DTR data, we reconstruct the long-term variations of photosynthetic activity in our study area prior to the satellite era (Figure 3). This reconstruction shows high spring and summer photosynthetic activity in the 1970's, followed by low activity in the mid to late 1980's. The high activity in the 1990's, concurrent with the satellite period, thus reflects a recovery from these low values and demonstrates the decadal variability of plant activity but no longterm trend.

[12] To gain a better understanding of the observed variations, we compare the interannual variability of our three indices with normalized temperature and precipitation (expressed by SPI3) anomalies averaged seasonally over the region (Figure 3 ). The long-term regional variations of the indices, derived from the daily local day-night difference in temperature, are related to the monthly averaged temperature and precipitation. In summer, the variability in SPDI (Figure $3 \mathrm{a}$ ) is correlated with the variability in precipitation $\left(\mathrm{r}=0.81, \mathrm{p}=2 \cdot 10^{-8}\right)$ and less correlated with temperature $(\mathrm{r}=0.48, \mathrm{p}=0.006)$, confirming that moisture is the primary control in the summer in this region. During spring (Figure $3 \mathrm{~b}$ ), the variation in GODI is attributable to spring temperature (or alternatively "growing degree days") variability for years without strong drought-stress $(\mathrm{r}=0.69, \mathrm{p}=$ 0.001 for the period 1967-1984). However, extreme drought years (e.g., the late 1980s) show a delayed spring onset, suggesting a control of both moisture and temperature. This dual control is in contrast to model studies that use only temperature as a predictor of spring leaf out in midlatitude regions [e.g., Foley et al., 1996]. The additional variability in spring and summer, which is not captured by the climate variables, can be the result of changes in land-use, crops yields, or species composition. In the fall, no clear relationship appears between the variability of the end of the growing season and the SON temperature and precipitation variability (Figure $3 \mathrm{c}$ ). While the variability of GTDI is well correlated to the variability in NPP and NDVI (Figure 2c), none of these 3 variables is correlated with climate variability. This is in agreement with previous studies [Randerson et al., 1999], which found that the end of the growing season is less controlled by climate than the start.

[13] Thus, the photosynthesis variability in spring and summer in the study area responds to decadal variability in monthly mean temperature and precipitation, with no longterm trend.

\subsection{Discussion of the DTR Indices Method}

[14] DTR is derived from routine meteorological measurements and its wide availability and long record makes it a useful proxy for plant activity in water-stressed regions. Historically, phenological changes and tree ring data also provide similar proxies. However, while many phenological records show gaps, DTR remained continuously available over the last half century. Also, while tree ring data give an estimate of wood production that is integrated over the entire growing season [Kaufmann et al., 2004], the DTR method offers a complementary estimate of past-variations in both the beginning and the end of the growing season, as well as variations in the photosynthetic activity during summer.

[15] The estimation of summertime photosynthesis using SPDI has several shortcomings, including variations in DTR with: vegetation type, land-use and management, species composition, and non-vegetation effects (such as aerosols and solar radiation). For example, a decrease in surface incident shortwave radiation was observed from the 1960s to the 1990s [Stanhill and Cohen, 2001] which should cause lower summertime DTR values. Urbanization is also reported to decrease DTR [Kalnay and Cai, 2003]. However, no long-term trend is obvious in the summer DTR record in the past 32 years in our study area. The absence of such a DTR trend reinforces our conclusion that there was no secular increase in summer photosynthetic activity, since 
both an increase in photosynthesis and a decrease in radiation (and increased urbanization) should cause a decrease in DTR. Because of the potential station-to-station uncertainties introduced by these factors, we are not able to convert the DTR indices into quantified carbon fluxes, but the indices can still be used to deduce the regional scale, long-term variability of the vegetation. It is important to note that variability in the DTR maxima, and thus the inference of both GODI and GTDI, are not affected by long-term radiation and urbanization trends or by the vegetation type.

[16] We found a strong correlation between SPDI and precipitation, which we interpreted as variations in transpiration and hence photosynthesis. Alternatively, Dai et al. [1997] suggest a DTR-precipitation correlation can be explained by either the attenuation of solar irradiance at the surface by precipitating clouds or by surface evaporative cooling. We maintain our conclusion since 1) contrary to Dai's study, our analysis is based on cloud screened DTR and 2) in the eastern United States, $50-75 \%$ of surface evaporation is due to transpiration, while soil-evaporation contributes less than $10 \%$ (the rest is attributed to intercepted water) [Choudhury and DiGirolamo, 1998].

[17] The primary strength of the DTR method is that it uses readily available temperature data to extract the temperature and moisture driven signal of plant activity without the need for relatively sparse moisture data or precipitation data. This provides an independent crosscheck of the models that parameterize NPP based on inputs of both temperature and precipitation and find a decadal variability in summer NPP that follows the precipitation variability [Pan et al., 1998].

\section{Conclusions}

[18] In this study, we develop a novel approach for hindcasting long-term variations in the growing season on land. It represents an effective way to obtain a photosynthetic proxy in regions, such as the eastern US, where both moisture and temperature are important in spring onset given the limited availability of moisture data. By providing an expanded historical context using the DTR data, we conclude that over the last 32 years the vegetation there shows a natural decadal variability and not a secular, long term trend.

[19] Acknowledgments. This work is supported by National Science Foundation grant ATM-9987457, NASA EOS-IDS grants NAG5-9514 and NNG04GK34G, NASA Carbon Cycle Program grant NAG5-11200, and the WHOI Ocean and Climate Change Institute. This is WHOI contribution 11336. We thank the two anonymous reviewers for their helpful comments. The first two authors contributed equally to this article.

\section{References}

Barford, C. C., S. C. Wofsy, M. L. Goulden, J. W. Munger, E. H. Pyle, S. P. Urbanski, L. Hutyra, S. R. Saleska, D. Fitzjarrald, and K. Moore (2001), Factors controlling long- and short-term sequestration of atmospheric $\mathrm{CO}_{2}$ in a mid-latitude forest, Science, 294, 1688-1691.

Bishop, J. K. B., and W. B. Rossow (1991), Spatial and temporal variability of global surface solar irradiance, J. Geophys. Res., 96, 16,839-16,858.
Bonfils, C., I. Fung, S. Doney, and J. John (2004), On the detection of summertime terrestrial photosynthetic variability from its atmospheric signature, Geophys. Res. Lett., 31, L09207, doi:10.1029/ 2004GL019453.

Chen, M., P. Xie, J. E. Janowiak, and P. A. Arkin (2002), Global land precipitation: A 50 -yr monthly analysis based on gauge observations, J. Hydrometeorol., 3, 249-266.

Choudhury, B. J., and N. E. DiGirolamo (1998), A biophysical processbased estimate of global land surface evaporation using satellite and ancillary data-I. Model description and comparison with observations, J. Hydrol., 205(3-4), 164-185.

Collatz, G. J., L. Bounoua, S. O. Los, D. A. Randall, I. Y. Fung, and P. J. Sellers (2000), A mechanism for the influence of vegetation on the response of the diurnal temperature range to changing climate, Geophys. Res. Lett., 27, 3381-3384.

Dai, A., A. D. DelGenio, and I. Y. Fung (1997), Clouds, precipitation and temperature range, Nature, 386, 665-666.

Durre, I., and J. M. Wallace (2001), The warm season dip in diurnal temperature range over the eastern United States, J. Clim., 14(3), 354-360.

Foley, J. A., I. C. Prentice, N. Ramankutty, S. Levis, D. Pollard, S. Sitch, and A. Haxeltine (1996), An integrated biosphere model of land surface processes, terrestrial carbon balance, and vegetation dynamics, Global Biogeochem. Cycles, 10, 603-628.

Hansen, J., R. Ruedy, J. Glascoe, and M. Sato (1999), GISS analysis of surface temperature change, J. Geophys. Res., 104, 30,997-31,022.

Kalnay, E., and M. Cai (2003), Impact of urbanization and land-use change on climate, Nature, 423, 528-531.

Kalnay, E., et al. (1996), The NCEP/NCAR 40-year reanalysis project, Bull. Am. Meteorol. Soc., 77(3), 437-471.

Kaufmann, R. K., R. D. D'Arrigo, C. Laskowski, R. B. Myneni, L. Zhou, and N. K. Davi (2004), The effect of growing season and summer greenness on northern forests, Geophys. Res. Lett., 31, L09205, doi:10.1029/ 2004GL019608.

Leathers, D. J., M. A. Palecki, D. A. Robinson, and K. F. Dewey (1998), Climatology of the daily temperature range annual cycle in the United States, Clim. Res., 9(3), 197-211.

Levis, S., and G. B. Bonan (2004), Simulating springtime temperature patterns in the Community Atmosphere Model coupled to the Community Land Model using prognostic leaf area, J. Clim., 17(23), 45314540.

Pan, Y. D., et al. (1998), Modeled responses of terrestrial ecosystems to elevated atmospheric $\mathrm{CO}_{2}$ : A comparison of simulations by the biogeochemistry models of the Vegetation/Ecosystem Modeling and Analysis Project (VEMAP), Oecologia, 114(3), 389-404.

Randerson, J. T., M. V. Thompson, C. M. Malmstrom, C. B. Field, and I. Y. Fung (1996), Substrate limitations for heterotrophs: Implications for models that estimate the seasonal cycle of atmospheric $\mathrm{CO}_{2}$, Global Biogeochem. Cycles, 10, 585-602.

Randerson, J. T., C. B. Field, I. Y. Fung, and P. P. Tans (1999), Increases in early season ecosystem uptake explain recent changes in the seasonal cycle of atmospheric $\mathrm{CO}_{2}$ at high northern latitudes, Geophys. Res. Lett., $26,2765-2768$

Schwartz, M. D. (1996), Examining the spring discontinuity in daily temperature ranges, J. Clim., 9(4), 803-808.

Schwartz, M. D., and J. M. Caprio (2003), North American First Leaf and First Bloom Lilac Phenology Data, Data Contrib. Ser. 2003-078, http:// www1.ncdc.noaa.gov/pub/data/paleo/phenology/north america lilac.txt, Natl. Geophys. Data Cent., Boulder, Colo.

Stanhill, G., and S. Cohen (2001), Global dimming: A review of the evidence for a widespread and significant reduction in global radiation with discussion of its probable causes and possible agricultural consequences, Agric. For. Meteorol., 107(4), 255-278.

Tucker, C. J., J. E. Pinzon, M. E. Brown, D. Slayback, E. W. Pak, R. Mahoney, E. Vermote, and N. ElSaleous (2005), An extended AVHRR 8-km NDVI data set compatible with MODIS and SPOT vegetation NDVI data, Int. J. Remote Sens., in press.

A. Angert, S. Biraud, C. Bonfils, I. Fung, and C. C. Henning, Berkeley Atmospheric Sciences Center, University of California, Berkeley, CA 94720, USA. (cbonfils@ucmerced.edu)

S. C. Doney, Marine Chemistry and Geochemistry, Woods Hole Oceanographic Institution, Woods Hole, MA 02543, USA. 